\title{
A LEI No 9.099/95 E SUAS INCONGRUÊNCIAS: BREVE ANÁLISE
}

\section{Thiago Pinho de Andrade}

Especialista em Direito Processual pela FA7. Advogado. thiagojusandrade@gmail.com

Sumário: Introdução. 1) Princípios orientadores. 2) Incongruências e dissonâncias. Conclusão.

Resumo: Este estudo surgiu da necessidade de se promover atividade cognitiva acerca das inobservâncias no âmbito de atuação da Lei no 9.099/95 (Juizados Especiais). Objetiva-se fazer uma análise perfunctória da referida lei, abordando, sobretudo, seus princípios orientadores explicitados nesta espécie normativa, vez que se trata de uma lei eminentemente de cunho principiológico. Desse modo, tentar-se-á abordar de forma objetiva tais princípios norteadores, ocasião em que ficará latente o escopo desta Justiça Especializada, para depois traçar breve e sutil paralelo com as interpretações e praxes flexibilizadoras que se vêm imprimindo àquela. Desta feita, poder-se-á observar que estão se desvirtuando os comandos contidos na lei em análise, promovendo um afastamento de seu real objetivo, que é em primeira instância a conciliação e resolução simples, informal, econômica, célere, das demandas que pousam sobre este instrumento descomplicador. Portanto, percebe-se que é indispensável que haja um esforço mútuo para descomplicar tal lei, para assim, fomentar seu coerente manejo.

Palavras-chave: Juizados Especiais. Princípios Orientadores. Interpretação. Praxes. Coerente manejo.

\section{INTRODUÇÃO}

Transcorridas mais de duas décadas da Carta Maior, percebe-se o latente discurso e razoáveis tentativas de se implementar, com tom significativo de ascendência, o tão desejado ideal de acesso à Justiça de forma ampla. Cada vez mais, busca-se elastecer tal foco com o objetivo de conferir o máximo de eficácia e efetividade à tutela jurisdicional ao cidadão, tentando-se observar os notáveis parâmetros, em tese, do Estado Democrático de Direito.

Incontestavelmente, o acesso à Justiça foi uma das grandes preocupações da Constituição Federal de 1988, uma vez que o instituto ora em análise (tomando-o 
como exemplo isolado) obteve status constitucional vindo a integrar o art. 98, I, o qual prevê a obrigatoriedade dos Juizados Especiais. Ademais, como exige a nova hermenêutica constitucional, não basta proclamar direitos, é preciso efetivá-los.

Desse modo, partindo da amplitude daquele postulado, bem como observando o grau máximo desejado para a concretização da tutela ao cidadão, criou-se, ou melhor, aperfeiçoou-se a respeitável idéia de uma nova justiça (para alguns) e/ou um novo procedimento (para outros) com o escopo de simplificar tal acesso e como maneira de aproximar o cidadão da Justiça.

$\mathrm{O}$ instrumento inovador ora mencionado foi criado inicialmente pela Lei 7.244/84, a qual estabelecia e regulava a criação e funcionamento dos Juizados Especiais de Pequenas Causas, os quais tinham competência o julgamento das causas de até vinte salários mínimos. Posteriormente, ante a grande procura desta "Justiça simplificada", o legislador infraconstitucional resolveu aprimorar tal procedimento com a Lei 9.099/95, a qual dispõe, de forma mais detalhada, acerca dos Juizados Especiais Cíveis e Criminais.

Nesse diapasão, tendo em vista o intuito primeiro deste instituto simplificar a tutela jurisdicional, aproximando mais o cidadão do Judiciário - percebe-se, sob uma ótica crítica, que tal objetivo foi atingido de maneira comedida, porém deixa transparecer alguns pontos conturbados que merecem ser revistos e, quiçá, modificados.

\section{PRINCÍPIOS ORIENTADORES}

A Lei $\mathrm{n}^{\circ}$. 9.099/95 é eminentemente processual de cunho principiológico (transcende o caráter meramente regulamentar e sistemático), reunindo em seus comandos normativos iniciais os parâmetros e diretrizes norteadores deste "novo procedimento" implementador de um maior acesso à Justiça.

\subsection{Princípios Constitucionais Intrínsecos}

É evidente que, por detrás dos princípios específicos da Lei 9.009/95, existe uma grande influência, direta e indiretamente, de vários princípios constitucionais, os quais não poderão ser abordados completamente ante a natureza sucinta deste artigo. Todavia, salientar-se-ão dois princípios assaz significativos e que, com toda certeza, guardam relação frontal com o cerne da problemática a ser enfrentada, a saber: Princípio da Dignidade da Pessoa Humana e Devido Processo Legal.

\subsubsection{A dignidade DA PESSOA HUMANA}

A dignidade da pessoa humana deve ser o valor máximo a ser preservado e buscado por este novel sistema, pois, caso contrário, o objetivo deste, aproximar 
o cidadão do Judiciário, seria de ordem inatingível. Os direitos e garantias fundamentais devem ser incansavelmente observados, para assim, não afastar o mínimo legal de dignidade do cidadão.

A dignidade é essencialmente um atributo da pessoa humana. Logo, pelo simples fato de ser humana, a pessoa merece todo o respeito, independentemente de sua origem, raça, sexo, idade, estado civil ou condição social e econômica.

Ademais, é de bom alvedrio mencionar que a Constituição Federal de 1988, foi a primeira constituição brasileira que explicitamente embasou toda a ordem legal com tal princípio fundamental. A dignidade da pessoa humana tem lugar privilegiado entre os princípios fundamentais da federação brasileira, enquanto Estado Democrático de Direito (art. $1^{\circ}, \mathrm{CF} / 88$ ).

Desse modo, é necessário ressaltar que, com foco nesta homenageada dignidade, deve-se buscar, de forma eficiente, o pleno acesso do cidadão à Justiça, de maneira sensível à necessidade do jurisdicionado que busca sua tutela no caso concreto.

\subsubsection{O DEVIDO PROCESSO LEGAL}

Não se pode inovar de forma desregrada, nem tampouco olvidar os princípios constitucionais basilares da sistemática processual pátria. Desse modo, calha aduzir que o princípio do devido processo legal deve ser estritamente observado de forma que esse novo procedimento não se transforme em uma justiça arbitrária sob a vã justificativa de estar se seguindo a linha principiológica da Lei 9.099/95.

Desta feita, o devido processo legal (art. $5^{\circ}$, caput, LIV, CF/88) como forma de garantia de observância das regras processuais vigentes, de forma integral, é um postulado efetivador da correta aplicação do rito procedimental previsto em cada caso concreto.

Tal postulado demonstra-se tão importante que, os demais regramentos processuais previstos na Constituição Federal, são tidos, doutrinariamente, como desdobramentos do devido processo legal. Corroborando esta assertiva, Nelson Nery Junior:

Bastaria a Constituição Federal de 1988 ter enunciado o princípio do devido processo legal, e o caput e a maioria dos incisos do art. $5^{\circ}$, seriam absolutamente despiciendos. De todo modo, a explicitação das garantias fundamentais derivadas do devido processo legal, como preceitos desdobrados nos incisos do art. $5^{\circ}$, $\mathrm{CF}$, é uma forma de enfatizar a importância dessas garantias, norteando a administração pública, o Legislativo e o Judiciário para que possam aplicar a cláusula sem maiores indagações (2002, p.42).

Nesse ponto, o princípio em tela não pode deixar de ser um justo processo legal, uma vez que não só a decisão que concretiza o direito substancial da parte 
deve ser justa, mais ainda, a condução do procedimento (seja ele qual for, de acordo com o caso concreto) até seu exaurimento deve seguir um caminho de justiça.

Justiça essa que jamais poderá tornar-se injustiça em nome de um injustificável culto à forma, ocasião em que deve haver um convívio saudável entre esta e aquela.

Portanto, os magistrados deste inovador "braço" da justiça deve redimensionar a principiologia da Lei ${ }^{\circ}$ 9.099/95 de acordo com os macrovalores constitucionais, de forma a fortalecer a prestação jurisdicional e o exercício da cidadania, para assim começarmos a efetivar um verdadeiro Estado Democrático de Direito.

\subsection{Princípios específicos}

Os artigos introdutórios da Lei 9.099/95 explicitam os princípios orientadores dos Juizados Especiais, os quais, como já dito alhures, sempre visa atingir o maior números de jurisdicionados necessitados, tendo como norte perene a busca pela conciliação entre as partes.

Vale ressaltar, por oportuno, que se deve sempre observar tais regramentos da Lei n 9.099/95, todavia, nos casos em que há omissão desta, pode-se utilizar supletivamente o Código de Processo Civil, porém, de forma assaz consciente e correlata.

\subsubsection{Princípio da oralidade}

Tem como objetivo concentrar os atos processuais e o seu desenrolar na forma oral. A forma escrita, em sede de Juizados Especiais, só é obrigatória quando prevista em lei. Segundo Chiovenda (1998, p. 61-67), para que seja outorgado o timbre da oralidade a um determinado processo, impõem-se as seguintes regras:

[....] prevalência da palavra como meio de expressão combinada com uso de meios escritos de preparação e de documentação; imediação da relação entre o juiz e as pessoas cujas declarações deve apreciar; identidade das pessoas físicas que constituem o juiz durante a condução da causa; concentração do conhecimento da causa num único período (debate) a desenvolver-se numa audiência ou em poucas audiências contíguas (princípio da concentração); e, finalmente, irrecorribilidade em separado das interlocutórias.

Desse modo, tal princípio, como se pode perceber, propicia uma maior aproximação das partes de seu juiz natural, como também torna menos longa e burocrática a caminhada processual. Logo, há uma prevalência pela busca da verdade material em detrimento da verdade formal, para assim combater o formalismo exagerado e ineficiente.

Nesse espeque, a dita oralidade e sua manifestação mais significativa é a realização da audiência de instrução e julgamento, ato mais importante deste procedimento, a qual deve ser única (quando possível) de modo a não se perder as vantagens da imediatidade do contato entre juiz e as provas. 


\subsubsection{PRINCÍPIO DA SIMPLICIDADE E DA INFORMALIDADE}

A simplicidade tem em seu bojo uma perspectiva de efetiva descomplicação do procedimento. A informalidade tem como escopo o máximo afastamento de fórmulas procedimentais que tornam o processo inacessível e incompreensível.

Independentemente da forma adotada, os atos processuais são considerados válidos sempre que atingirem suas finalidades (art. 13 da Lei 9099/95). Parafraseando Cristina Tereza Gaulia, "processo é meio e não fim, razão pela qual nenhuma nulidade é reconhecida sem a demonstração do prejuízo (art. 13, § $1^{\circ}$ )."

Nesse contexto, pode-se asseverar com veemência que a simplicidade fundida à informalidade resulta no princípio "maior" da instrumentalidade das formas, o qual valida o ato processual que preencher sua finalidade para que foi realizado, observando os critérios do art. $2^{\circ}$ da Lei $n^{\circ}$ 9.099/95.

\subsubsection{PRINCÍPIO dA ECONOMIA PROCESSUAL}

A economia processual está intimamente ligada à celeridade e à simplicidade e informalidade. A desburocratização dos atos processuais, a busca pela simplicidade destes, a implementação de agilidade, entre outros, são vertentes do princípio da economia processual.

Tal princípio que visa, cada vez mais, buscar atingir a simplicidade e descomplicar o procedimento, deve ser efetivado, sobretudo, pelos servidores judiciais que muitas vezes inviabilizam a prestação jurisdicional pelo apego excessivo ao formalismo.

Desse modo, a economia processual sinaliza para a estrutura e operacionalização processual, deixando um pouco de lado a matéria jurídica propriamente dita e a ser discutida, sempre buscando a qualidade total dos atos processuais e, por conseguinte, a instrumentalização dos atos e formas processuais.

\subsubsection{PrincíPIO dA CELERIDADE}

O princípio da celeridade está relacionado ao fator tempo, o qual observa o processo e a chegada da ação na esfera judicial desde o momento de seu protocolo até o momento em que se tem a efetiva solução do conflito. Deve-se, no âmbito dos JECCs, sempre observar meios que efetivem tal postulado.

Todavia, mesmo sendo tal postulado a consagração pela busca incessante pela efetividade da prestação jurisdicional, jamais pode-se olvidar ou descumprir o devido processo legal, observando vigorosamente seus inafastáveis corolários, quais sejam, ampla defesa e o contraditório. 
Por derradeiro, vale salientar por oportuno que, a Emenda Constitucional $\mathrm{n}^{\mathrm{o}} 45 / 04$ acrescentou postulado (art. $5^{\circ}$, LXXVIII, CF/88) ${ }^{1}$ inovador no rol dos direitos e garantias fundamentais, o qual trata, justamente, da busca consciente pela celeridade, não deixando de observar a razoável duração do processo.

\section{INCONGRUÊNCIAS E DISSONÂNCIAS}

Hodiernamente, após mais de dez anos da Lei no 9.099/95, e aparentemente viver-se um período de estabilidade e suposta "perfeição", muito se discute, ainda, acerca de pontos específicos da dita lei em que há um choque entre legislação, entendimentos superiores, interpretações ou até mesmo divergências e contradições na própria lei. Desse modo, ante esse sutil aspecto de divergências e fomento à discussão, importante ressaltar algumas dissonâncias que merecem revisão para aperfeiçoar este significativo procedimento.

\subsection{Prova Pericial}

Professores e processualistas de vasta experiência afirmam que não é possível a produção de prova pericial no âmbito dos Juizados Especiais, pois há incompatibilidade daquela com os princípios orientadores deste procedimento, sobretudo o princípio da celeridade.

Entretanto, tal afirmação não é integralmente verídica ou pelo menos deve ser relativizada, senão vejamos dispositivo da Lei 9.009/95, o qual reproduz dispositivo do CPC (Art. 332, CPC):

Art. 32 - Todos os meios de prova moralmente legítimos, ainda que não especificados em lei, são hábeis para provar a veracidade dos fatos alegados pelas partes.

Ademais, além da prova pericial não se configurar apenas naquela perícia formal, houve profundas mudanças com o advento da lei $\mathrm{n}^{\mathrm{o}} 8.455 / 92^{2}$, as quais atenuaram o rigor exacerbado e formal da demorada prova pericial original. Saliente-se, ainda, que tal lei inovadora trouxe modificação ao parágrafo segundo do art. 421 do CPC:

\footnotetext{
1 Art. 5, LXXVIII, CF/88 - a todos, no âmbito judicial e administrativo, são assegurados a razoável duração do processo e os meios que garantam a celeridade de sua tramitação.

2 Esta Lei alterou dispositivos referentes à prova pericial.
} 
Art.421, parágrafo segundo, CPC - Quando a natureza do fato o permitir, a perícia poderá consistir apenas na inquirição pelo juiz do perito e dos assistentes, por ocasião da audiência de instrução e julgamento a respeito das coisas que houverem informalmente examinado ou avaliado.

Ora, tal prova não deixa de ser pericial, é a dita perícia informal (alguns intérpretes preferem chamar de prova técnica, o que não desconfigura o seu caráter pericial), a qual possibilita a oitiva do perito pelo juiz e dispensa o laudo técnico. Desse modo, calha elucidar que, mais uma vez demonstrando descompasso entre operadores do Direito e a legislação a ser observada, a Lei n ${ }^{0}$ 9.099/95 prevê tal perícia informal:

Art. 35 - Quando a prova do fato exigir, o Juiz poderá inquirir técnicos de sua confiança, permitida às partes a apresentação de parecer técnico.

Parágrafo único - No curso da audiência, poderá o Juiz, de ofício ou a requerimento das partes, realizar inspeção em pessoas ou coisas, ou determinar que o faça pessoa de sua confiança, que lhe relatará informalmente o verificado.

Nesse contexto, corroborando ao entendimento esposado neste ensaio, compartilham os magistrados Louri Geraldo e Denise Retamero, litteris:

É a chamada perícia informal ou alternativa, mas perícia, onde se dispensa a apresentação do laudo e o Juiz apenas ouve o perito em audiência. Assim, entendemos perfeitamente cabível a prova pericial no Juizado Especial Cível; não a formal, mas a informal, com a oitiva do perito e a apresentação de parecer técnico pelas partes. ${ }^{3}$

Ademais, tem-se entendimento orientador do Fórum Nacional dos Juizados Especiais (FONAJE) que converge com o entendimento supramencionado, vejamos:

Enunciado 12 - A perícia informal é admissível na hipótese do art. 35 da Lei 9.099/1995.

Por derradeiro, vale mencionar posicionamento afim dos juristas Nancy Andrighi e Sidnei Beneti:

Considerar incabível a prova pericial, ainda que informal, seria impedir a efetividade do processo e a busca da verdade real, princípios imperativos nos Juizados Especiais (1996, p.49).

3 Publicado pelo Instituto dos Magistrados do Brasil, n.12. Revista In Verbis, disponível em $<$ http:www. inverbis.com.br> 
Portanto, percebe-se a incompatibilidade da perícia formal, vez que há concentração do conjunto probatório em audiência de instrução, sem contudo prescindir a perícia informal, perfeitamente cabível em sede de Juizado. Logo, deve-se saber diferenciar uma da outra, o que a legislação poderia ter sido mais clara, para não haver indeferimento de iniciais (como se vê bastante) por não saber fazer a distinção de uma e outra.

\subsection{Comparecimento PESSOAl ÀS AUdiênCIAS}

A legislação que rege o procedimento sob análise é taxatixa no tocante ao comparecimento pessoal das partes às audiências, in verbis:

Art. $9^{\circ}$ da Lei 9.099/95 - Nas causas de valor até vinte salários mínimos, as partes comparecerão pessoalmente, podendo ser assistidas por advogado; nas de valor superior, a assistência é obrigatória.

O próprio FONAJE, fórum orientador das praxes dos JECCs, consolidou e editou entendimento que converge à pessoalidade acima referida:

Enunciado 20 - O comparecimento pessoal da parte às audiências é obrigatório. A pessoa jurídica poderá ser representada por preposto.

Todavia, pecam pelo rigorismo exacerbado e esquecem que a Lei $n^{\circ} 9.099 / 95$ é de cunho principiológico, ou seja, todos os seus princípios convergem para uma relativização do rigor da lei e, sobretudo, deve-se analisar o caso concreto.

Desta feita, é costumeiro se ver e presenciar absurdos jurídicos que vão de encontro aos princípios orientadores. Exemplo disso é a situação em que por motivo de força maior uma das partes falta à audiência, porém se faz representar por seu advogado ou familiar, e não se pode transigir, mesmo havendo toda uma conjuntura favorável, por apego à insensata pessoalidade trazida pela lei.

Nesse contexto, há esforços de poucos para relativizar tal regramento "absoluto" que desvirtua o intuito do instituto em análise. Desta feita, a Turma Recursal do Estado do Rio Grande do Sul, vem flexibilizando a referida representação pessoal:

EMENTA: RÉ NÃO CITADA PESSOALMENTE E RESIDENTE EM SALVADOR/BA. CIÊNCIA INDIRETA DA EXISTÊNCIA DO FEITO E OUTORGA DE PROCURAÇÃO AO SEU IRMÃO PARA REPRESENTÁ-LA NO PROCESSO, INCLUSIVE COM PODERES PARA ACORDAR. A regra que exige o comparecimento pessoal das partes pressupõe situações normais, 
em que ambas as partes residem na mesma comarca. Tal exigência pode ser afastada, quando uma das partes reside em lugar muito distante. Revelia indevidamente decretada. Recurso provido para cassar a sentença. ${ }^{4}$

Além de desrespeitar os princípios trazidos no art. $2^{\circ}$ da Lei 9.099/95, inobserva princípio maior desta justiça especializada, qual seja, a busca prioritária pela conciliação.

Exemplo outro é a presença de uma das partes na pessoa de seu advogado, e mais uma vez a impossibilidade de presença pessoal do autor por motivo de força maior. Porém, ocorre o não comparecimento da parte demandada, o que, em tese ensejaria a decretação da revelia e a consumação de seus efeitos, ocasião em que mesmo diante desta omissão tal audiência acaba por ser adiada, inviabilizando a referida garantia processual e, sobretudo, ferindo, mais uma vez, a principiologia do procedimento em tela.

Nesse diapasão, calha asseverar que o art. 51, I da Lei $n^{\circ}$ 9.099/95', apenas prevê a extinção do processo quando o autor deixar de comparecer a qualquer das audiências do processo. Porém, não há vedação para que o autor compareça às audiências por meio de representante legalmente constituído. Há, tão-somente, a vedação de não se ausentar daquele ato processual (audiência).

Portanto, conclui-se que não há previsão constitucional para a vedação supramencionada, afinal, essa vedação constitui inequívoca restrição ao direito constitucional de acesso à Justiça, promovida pela determinação da presença física da parte às audiências.

\subsection{VALOR DA CAUSA}

Outra dissonância entre intérpretes e a lei trazida à baila, é a que diz respeito à competência dos JECCs sobre o critério do valor atribuído à causa. Como é de palmar sabença, a competência para processamento da ação, em sede de Juizados Especiais, não pode exceder o valor de quarenta salários mínimos:

Art. $3^{\circ}$ da Lei 9.099/95 - O Juizado Especial Cível tem competência para conciliação, processo e julgamento das causas cíveis de menor complexidade, assim consideradas: I - as causas cujo valor não exceda a 40 (quarenta) vezes o salário mínimo;

${ }^{4}$ BRASIL, Terceira Turma Recursal do Estado do Rio Grande Do Sul, Recurso Cível No 71000616912 , Recorrente Marga Luiza Franke Boff, Recorrido Elizabet Teresinha Paulo, Porto Alegre/RS, 15/03/2005.

5 Art. 51. Extingue-se o processo, além dos casos previstos em lei: I - quando o autor deixar de comparecer a qualquer das audiências do processo; 
Para não tornar tal regramento algo absoluto, tornando-o compatível com a Lei 9.099/95, admite-se uma flexibilização a tal critério, qual seja, a renúncia ao crédito que exceder o valor de referência admitido neste procedimento, litteris:

Art $3^{\circ}, \S 3^{\circ}$, Lei 9.099/95 - A opção pelo procedimento previsto nesta Lei importará em renúncia ao crédito excedente ao limite estabelecido neste artigo, excetuada a hipótese de conciliação.

Ora, percebe-se claramente que se deve observar o limite do valor da causa há pouco referido, como também transigir em causas de valores que excedam tal parâmetro, porém com a consciente disposição que a renúncia ao valor excedente é imprescindível e obrigatória.

Desta feita, contrário ao que se dispõe tal lei, o Superior Tribunal de Justiça ${ }^{6}$, vem dando entendimento mais amplo a tal dispositivo, o que parece não ser coerente ao escopo da Lei dos Juizados Especiais.

Juizados especiais podem julgar ações com valor superior a 40 salários mínimos. A Terceira Turma do Superior Tribunal de Justiça decidiu que as ações em juizados especiais podem ter valor maior que 40 salários mínimos.Segundo explicou a ministra Nancy Andrighi, o valor da causa é um dos critérios para a definição da competência do juizado, sendo, porém, admissível que às vezes esse teto seja ultrapassado. Ao suspender decisão do Tribunal de Justiça de Santa Catarina sobre a matéria, Nancy Andrighi observou que, na definição da competência dos juizados, foram utilizados dois critérios distintos - quantitativo e qualitativo - para definir o que são causas cíveis de menor complexidade. Segundo ela, exige-se, de regra, a presença de apenas um desses dois requisitos e não a sua cumulação. A exceção, conforme a ministra, fica para as ações de posse de bens imóveis. Como o processo sobre a competência do Juizado Especial foi determinada com base num acidente de trânsito na cidade de Lages, os ministros consideraram admissível que o pedido excedesse o limite de 40 salários mínimos.

Ademais, a Lei n ${ }^{\circ}$ 9.099/95 é assaz taxativa ao valor da causa e seu excedente, o que não se pode admitir tal interpretação sob pena de se abrir precedentes a uma absoluta flexibilização daquela, tornando-a inviável e usurpando sua credibilidade para com o jurisdicionado, pois ficaria este, caso tentasse enveredar pelo posicionamento do Tribunal Superior, à mercê do entendimento do magistrado.

Logo, deve-se deixar claro o que a lei autoriza e o que a jurisprudência e entendimentos outros ampliam tal campo de legalidade daquela espécie normativa.

6 Sala de Notícias. Juizados Especiais podem julgar ações com valor superior a 40 salários mínimos. www.stj.jus.br 
Corre-se o sério e iminente risco do cidadão, sem jurídica representação, ficar sem saber o que fazer e o que pedir.

\subsection{CitaÇão POR EDital}

Ponto outro controverso é a citação por edital, a qual ainda traz divergência de pensamentos, inclusive jurisprudencial, no que tange ao seu cabimento ou não. Para ser mais objetivo, a Lei 9.099/95 veda expressamente a possibilidade de realização de tal expediente, in verbis:

Art. 18, da Lei no 9099/95 - A citação far-se-á: I - por correspondência, com aviso de recebimento em mão própria; II - tratando-se de pessoa jurídica ou firma individual, mediante entrega ao encarregado da recepção, que será obrigatoriamente identificado; III - sendo necessário, por oficial de justiça, independentemente de mandado ou carta precatória. $\S 2^{\circ}$ - Não se fará citação por edital.

Contudo, mesmo diante de tal vedação explícita, o Fórum Nacional dos Juizados Especiais, editou enunciado que vai de encontro com tal disposição normativa, causando, novamente, instabilidade à Lei ora em análise, litteris:

Enunciado 37 - Em exegese ao art. 53, $\S 4^{\circ}$, da Lei n ${ }^{\circ}$ 9.099/1995, não se aplica ao processo de execução o disposto no art. $18, \S 2^{\circ}$, da referida lei, sendo autorizados o arresto e a citação editalícia quando não encontrado o devedor, observados, no que couber, os arts. 653 e 654 do Código de Processo Civil. (Nova Redação aprovada no XXI Encontro - Vitória/ES).

Nesse contexto, calha asseverar, o que não podia ser diferente, que há total descompasso entre tal enunciado e a Lei $\mathrm{n}^{\circ}$ 9.099/95, tornando- a, mais uma vez, de difícil compreensão para o cidadão que esbarra em um ato processual relativizado como esse.

\section{Conclusão}

Desse modo, com recorrência se presenciam divergências entre a Lei $n^{\circ}$ 9.099/95 e seus intérpretes, jurisprudência, doutrina, o que não pode acontecer. Em ocasiões como essas, o bom senso manda debater e amadurecer tais idéias dissonantes, para depois tentar reformular o texto legal, principalmente quando se trata de uma lei como essa que tem amplo alcance e, muitas vezes, é manipulada por pessoas que não detêm conhecimentos jurídicos (o cidadão comum).

Nesse contexto, além de interpretações prematuras e que não condizem com o procedimento em análise, desrespeitam os princípios orientadores que 
a regulam, como também promove uma relativização desmedida do que está disposto em tal espécie normativa.

Nesse ponto, situação outra não acontece a não ser amargurar os efeitos destas divergências, no principal destinatário do procedimento simplificado dos JECCs, que é, em primeira e última instância, o cidadão que busca sua efetiva tutela jurisdicional.

Portanto, urge a premente necessidade de haver uma convergência entre as fontes do direito de maneira que haja uma promoção para uma efetiva publicidade "descomplicadora", sempre observando os postulados trazidos no bojo da Lei ${ }^{\circ}$ 9.099/95, para assim, fomentar o coerente manejo deste procedimento.

\section{REFERÊNCIAS}

ANDRIGHI, Fátima Nancy e BENETI, Sidnei. Juizados Especiais Cíveis e Criminais. Belo Horizonte: DeI Rey, 1996.

BRASIL. Código Civil e legislação civil em vigor / Theotonio Negrão e José Roberto F. Gouvêa. - 25. ed. atual. Até 6 de janeiro de 2006. - São Paulo: Saraiva, 2006.

BRASIL. Constituição (1988). Constituição da República Federativa do Brasil. Brasília, DF. Senado, 1988.

CHIOVENDA, Giuseppe. Instituições de Direito Processual Civil, vol. 3, 1. ed., Campinas: Bookseller, 1998.

FÓRUM NACIONAL DOS JUIZADOS ESPECIAIS -FONAJE. Disponível em: $<$ http: www.fonaje.org.br>. Acesso em: 13 jul. 2009

GAULIA, Cristina Tereza. Juizados Especiais Cíveis: o espaço do cidadão no Poder Judiciário, Rio de Janeiro: Renovar, 2005.

INSTITUTO DOS MAGISTRADOS DO BRASIL, Revista In Verbis, n.12, disponível em $\leq$ http:www.inverbis.com.br $>$. Acesso em: 17 jul. 2009

NERY Junior, Nelson. Princípios do processo civil na Constituição Federal, 7. ed. rev. e atual. com as Leis 10.352/2001 e 10.358/2001, São Paulo: Revista dos Tribunais, 2002.

NERY Junior, Nelson e NERY, Rosa Maria Andrade. Código de Processo Civil Comentado e Legislação Processual Civil Extravagante em Vigor. 4. ed. rev. ampl. atual. São Paulo: Revista dos Tribunais, 1999.

PRESIDÊNCIA DA REPÚBLICA: banco de dados. Disponível em:

$<$ http:www.presidencia.gov.br>. Acesso em:10 ul. 2009 
. Lei Federal n 9.099, de 26 de setembro de 1995.

. Lei Federal n 8.455, de 24 de agosto de 1992

. Lei Federal n 5.869, de 11 de janeiro de 1973.

ISSUES REGARDING BRAZIL'S FEDERAL

LAW N. 9.099/95

Abstract: This study focuses on Brazil's Law of Special Courts. As it is guided mainly by principles, it is shown here that the law has been drifting away from its original objectives, which are conciliation and swift problem resolution.

Keywords: Special Courts. Guiding principles. Interpretation. Practices. Consistent management. 